\title{
Nanograin formation in dimple ridges due to local severe-plastic-deformation during ductile fracture
}

\author{
Xiangnan Pan ${ }^{\mathrm{a}, \mathrm{b}}$, Guian Qian ${ }^{\mathrm{a}, \mathrm{b}}$, Youshi Hong ${ }^{\mathrm{a}, \mathrm{b}, *}$ \\ a State Key Laboratory of Nonlinear Mechanics, Institute of Mechanics, Chinese Academy of Sciences, Beijing 100190, China \\ ${ }^{\mathrm{b}}$ School of Engineering Science, University of Chinese Academy of Sciences, Beijing 100049, China
}

\section{A R T I C L E I N F O}

\section{Article history:}

Received 26 September 2020

Revised 30 October 2020

Accepted 3 November 2020

Available online $\mathrm{xxx}$

\section{Keywords:}

Nanograins

ductile fracture

dimple ridge

severe plastic deformation (SPD)

titanium alloy

\begin{abstract}
A B S T R A C T
Nanograin materials have superior properties in mechanics, physics and chemistry. Here, we found a new phenomenon that nanograin formation spontaneously occurs in the process of ductile fracture for a titanium alloy, and the dominating mechanism is local severe-plastic-deformation (LSPD). The microstructure evolution during the entire process of monotonic tension was revealed to further understand the ductile fracture from plastic deformation to necking, and to final failure, especially in the post uniform deformation stage, in which the voids nucleate, grow and coalesce. The process of the LSPD can potentially provide a new concept and approach to design and produce high ductile materials, in which nanograin formation will consume massive strain energy to enable the large elongation after specimen necking in the post uniform deformation.
\end{abstract}

(c) 2020 Acta Materialia Inc. Published by Elsevier Ltd. All rights reserved.
The subject of nanograin materials with the equivalent grain diameter smaller than $250 \mathrm{~nm}$ has been extensively investigated in materials science and engineering over the past decades. Due to the large fraction of grain boundaries (GBs), nanocrystalline materials have quite unique mechanical, physical and chemical properties in comparison with traditional crystalline materials with grain size between 10 and $250 \mu \mathrm{m}$ [1-3]. Described by the Hall-Petch relation [4,5], the nanostructured metals or alloys are certainly of high tensile strength. Therefore, nanograin-structures are applied to upgrade the mechanical properties of structural materials by microstructure designing and processing [6-8]. Severe plastic deformation (SPD) is one of the novel techniques to produce nanograins or refined microstructures [9-13]. During an SPD process, the strain energy resulted from irreversible plastic deformation was stored in the new born GBs of nanograins or interfaces of refined microstructures.

Here, we report a new phenomenon that nanograins are produced in the ridges of ductile dimples in the fracture surface layer of a titanium alloy (Ti-6Al-4V). We conclude that the formation mechanism of nanograins is the process of local SPD (LSPD) under monotonic tension. These findings not only further reveal the detailed mechanism in nanometer scale of ductile fracture but also will enrich the technique of SPD processing.

\footnotetext{
* Corresponding author.

E-mail address: hongys@imech.ac.cn (Y. Hong).
}

Ductile fracture is one of the most common failures of metallic materials subjected to monotonic or even cyclic loadings [14]. The investigations of ductile fracture were closely related to fracture mechanics [15-17], and many models were proposed to describe the fracture process of ductile materials based on the observations of void nucleation, growth and coalescence [17-22]. Similar investigations under cyclic loading conditions have also been accomplished by experiments [23-25] and theoretical analyses [26,27]. Although there are a large number of theoretical and experimental descriptions on ductile fracture, the real physical details in nanometer scale are still rare. In the practice of mechanical property research, yield strength, ultimate tensile strength $\sigma_{\mathrm{u}}$ (UTS) and uniform elongation (UE) are the most important parameters representing the tensile strength and the ductility of materials [28], but the physical behavior after uniform deformation of the tested specimen is less investigated. As well known, for many metals and alloys [14,17], there is a critical point at the tensile curve, after which strain hardening cannot compensate the area reduction of the cross section. After that point, the strain becomes localized, and this process of "post uniform deformation" is so called "necking". It is noted that some ductile materials still can sustain a considerable amount of plastic deformation in the post uniform deformation stage. In addition, for necked specimens, the ductile damage in terms of void formation and growth is accelerated from a point of the post uniform deformation. Consequently, it is worth paying attention to the stage of post uniform deformation for the research of ductility and fracture of materials. 


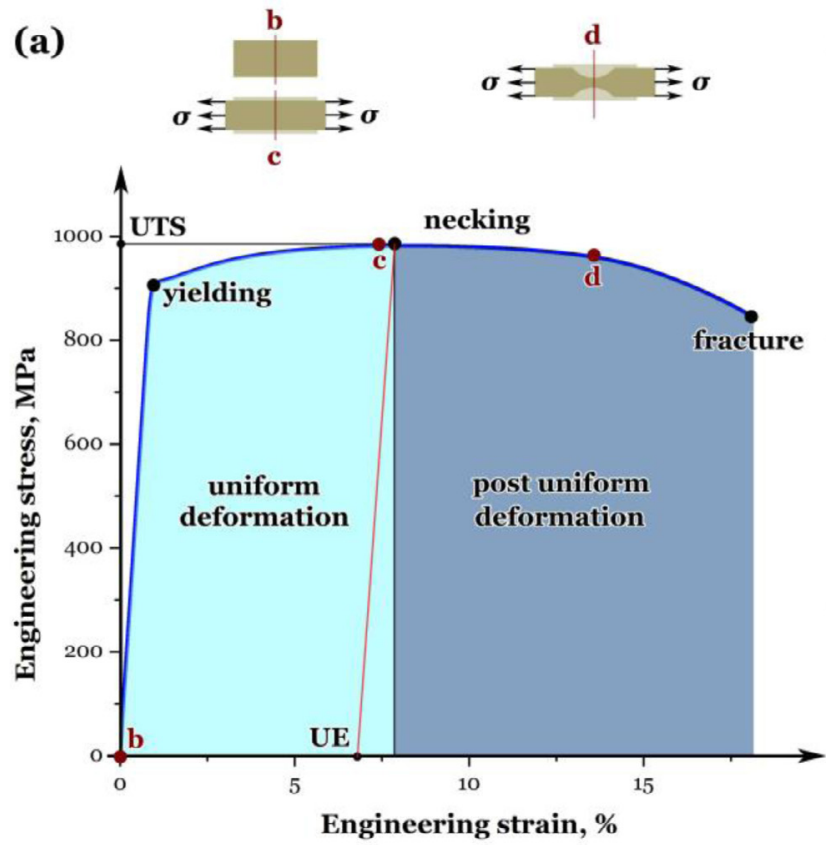

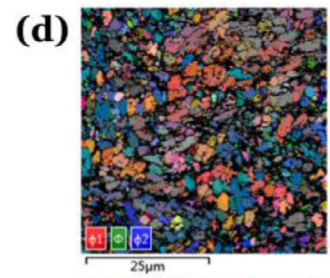

(c)
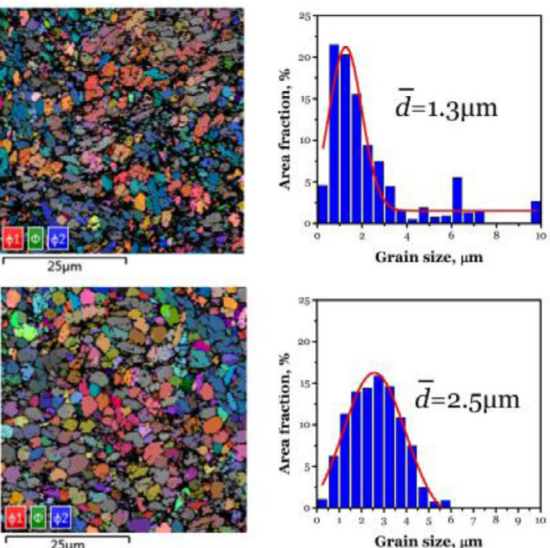

(b)
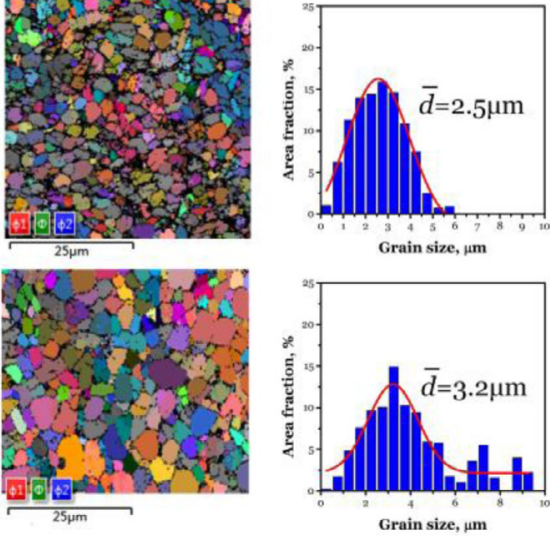

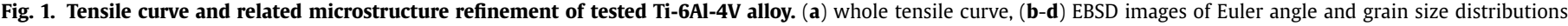
on the cross sections at points b-d of tensile curve.

We characterized the microstructure evolution of a titanium alloy under different strains from original state to final fracture, especially in the post uniform deformation regime, by scanning electron microscopy (SEM), electron backscatter diffraction (EBSD), focused ion beam (FIB) and transmission electron microscopy (TEM).

The material used in this investigation is a titanium alloy (Ti$6 \mathrm{Al}-4 \mathrm{~V}$ ) with the chemical composition (wt.\%) of $5.96 \mathrm{Al}, 4.13 \mathrm{~V}$, $0.16 \mathrm{Fe}, 0.02 \mathrm{C}, 0.015 \mathrm{~N}, 0.0036 \mathrm{H}, 0.18 \mathrm{O}$ and balance Ti, which was heat treated by the following procedure: (1) heated at $1193 \mathrm{~K}$ for 10 hours in vacuum $\left(<1 \times 10^{-3} \mathrm{~Pa}\right)$ followed by furnace cooling, (2) subjected to $2 \%$ plastic strain in tension, and (3) heated at 873 $\mathrm{K}$ for 1 hour followed by furnace cooling for stress relaxation and microstructure recrystallization. Thus the tested titanium alloy has the equiaxed microstructure (EM) consisting of equiaxed $\alpha$ grains and randomly distributed transformed $\beta$. The $\alpha$ phase possesses about $90 \%$ volume fraction ( $\alpha$ grains of about $75 \%$ plus $\alpha$ precipitates of about $15 \%$ in transformed $\beta$ domains). The tensile tests were conducted at room temperature, with three cylindrical specimens (dog-bone shape, $10 \mathrm{~mm}$ in diameter and $56 \mathrm{~mm}$ in gage length), in which the longitudinal direction is parallel to the axis of the received round bar and the strain rate is $10^{-4} \mathrm{~s}^{-1}$.

In SEM observations, a JEOL JSM-IT300 was used to take the fractographs of ductile dimples, and a Zeiss Merlin was used to examine the morphology in longitudinal sections of necked specimens. The EBSD results were acquired by using the Zeiss Merlin equipped with a NordlysNano detector. The TEM samples were prepared in the chamber of a FIB/SEM dual-beam system via an FEI Helios Nanolab 600i. The subsequent TEM observations were conducted by using an FEI Talos F200X and an FEI Tecnai G2 F30 $\mathrm{S}$-Twin. The microstructures of the fracture surface layer were examined by bright filed (BF) and dark field (DF) imaging, high resolution TEM (HRTEM), and selected area electron diffraction (SAD, diameter $180 \mathrm{~nm}$ ). The size of nanograins was measured from HRTEM images (a total of about 300 nanograins) by using the software of Image-Pro Plus 6.0.

Fig. 1a shows the tensile curve of the Ti-6Al-4V alloy, which contains uniform deformation and localized or post uniform deformation stages. Fig. $1 \mathrm{~b}$ to $\mathrm{d}$ presents the EBSD maps in terms of Euler angles and the obtained grain size distributions on the cross sections at points b-d of the tensile curve. It is obvious that the grain size refinement occurs in the plastically strained materials under monotonic tension. Meanwhile, the increasing fraction of zero resolution with black regions in the EBSD maps (Fig. 1b to d) implies that a growing amount of energy resulted from irreversible deformation was stored in the stretched specimen. According to the dislocation theory [14,29], the plastic strain energy is a function of the associated dislocation density. Actually, the zero resolution regions of EBSD should be attributed to the accumulation of dislocations [30].

Due to stress concentration, strain localization becomes more and more remarkable at the connecting areas between the voids in the necked region until final ductile fracture. Fig. 2a shows the dimple morphology on the center of the fracture surface of a broken specimen. There is no obvious morphological difference in fractographic feature for the ductile dimples. Thus, we randomly chose a location for TEM sampling by FIB milling marked by the red bar shown in Fig. 2a. Fig. $2 b$ presents the BF image of the TEM sample, showing the microstructure with vague GBs beneath the fracture surface of ductile dimples because of the high density dislocations within the grains. Fig. $2 \mathrm{c}$ is an enlarged DF image of box $b$ in the BF image showing the tearing ridge between the two adjacent dimples. In the region of the tearing ridge, several small bright granules of discrete nanograins prevail within the rim area beneath the fracture surface. Fig. $2 d$ to $g$ shows four SAD patterns for circular domains $d$ to $g$ each with the size of 180 $\mathrm{nm}$ in diameter. Fig. $2 \mathrm{~d}$ exhibits slightly elongated diffraction spots indicating that domain $\mathrm{d}$ at the "hill side" of the dimple experienced a considerable plastic deformation. Fig. 2e exhibits discontinuous diffraction rings indicating that domain e at the ridge or peak region contains a number of nanograins. Fig. $2 \mathrm{f}$ exhibits isolated diffraction spots indicating that domain $f$ at the "valley" of the adjacent dimple still remains the single grain with the size larger than $180 \mathrm{~nm}$. Fig. $2 \mathrm{~g}$ also exhibits the diffraction pattern of mono-crystal indicating that the location away from the fracture surface keeps the original coarse microstructure. The above results are the representatives of tens of similar observations. 

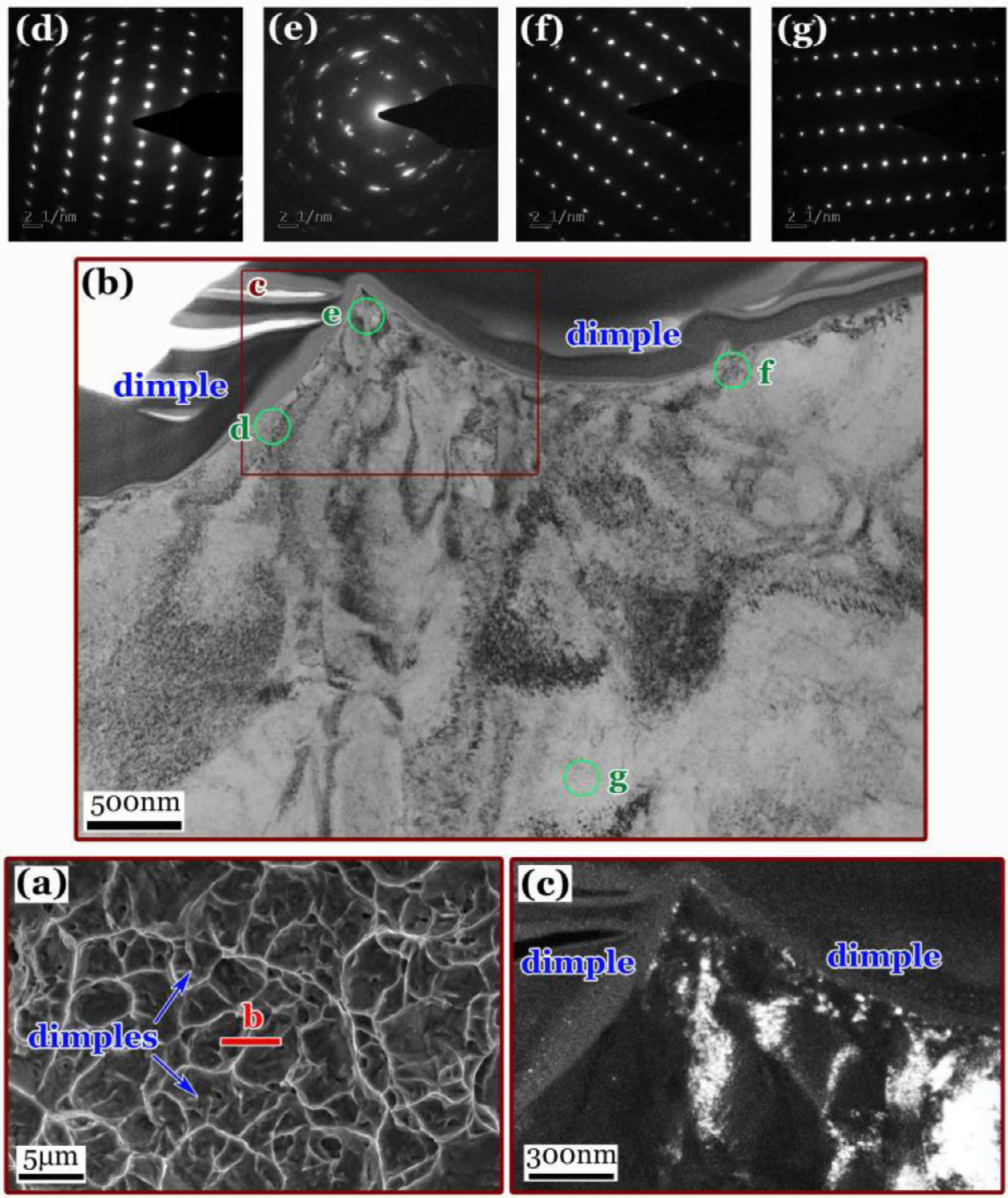

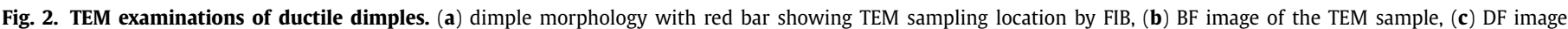
of box c in (b), and (d-g) SAD patterns for circular domains d-g in (b).

Another TEM sample was cut from a region of ductile dimples for the further examination of micro- and nanostructure features. Fig. 3a is an enlarged BF image showing the morphology of the tearing ridge and the surrounding region. High density dislocations are distributed in this image. Nanocrystalline morphology appears in the ridge region, and the SAD pattern (Fig. 3b) of polycrystalline indicates that several nanograins exist in the circular domain b within the region. Subsequently, we measured the nanograin size and obtained its distribution (Fig. 3c), showing the average nanograin diameter of $14 \mathrm{~nm}$. Furthermore, Fig. 3d gives an image of HRTEM for box d within the ridge region in Fig. 3a. It is seen that nanostructure with GBs is visible in the region of the tearing ridge.

The results of Figs. 2 and 3 evidently indicate that nanograin formation indeed occurs in the tearing ridge of ductile dimples. The size of nanocrystalline regions is of submicron scale between 300 and $500 \mathrm{~nm}$, where the nanograin size is about ten to several tens nanometers. For nanograined materials, the total area as well as the related specific fraction of GBs is extremely large, and then
GBs can consume a large amount of strain energy much more than that in the case of coarse grained materials. It should be emphasized that although the volume fraction of the GB region is very small, the stored energy cannot be underestimated in comparison with the whole region of the plastic deformed specimen. In this regard, the energy consumed by GBs and plastic deformation can be assessed by EBSD technique [30]. In fact, similar behavior of microstructure refinement and nanograin formation also occurs in cyclic cases, specifically inside the region of fatigue crack initiation for high-strength steels [31,32] and titanium alloys [33,34] under a negative stress ratio of very-high-cycle fatigue.

In cyclic loading, the microstructure refinement is governed by the NCP (numerous cyclic pressing) mechanism [31], in which an appropriate mode of applied stress and sufficient loading cycles are emphasized for the nanograin formation. In this context, for monotonic tension, Fig. 4 schematically explains the process of grain size refinement by an LSPD mechanism.

As shown in Fig. 4a, when the applied tensile stress reaches the UTS value, as the strain increases further, the tested material turns 

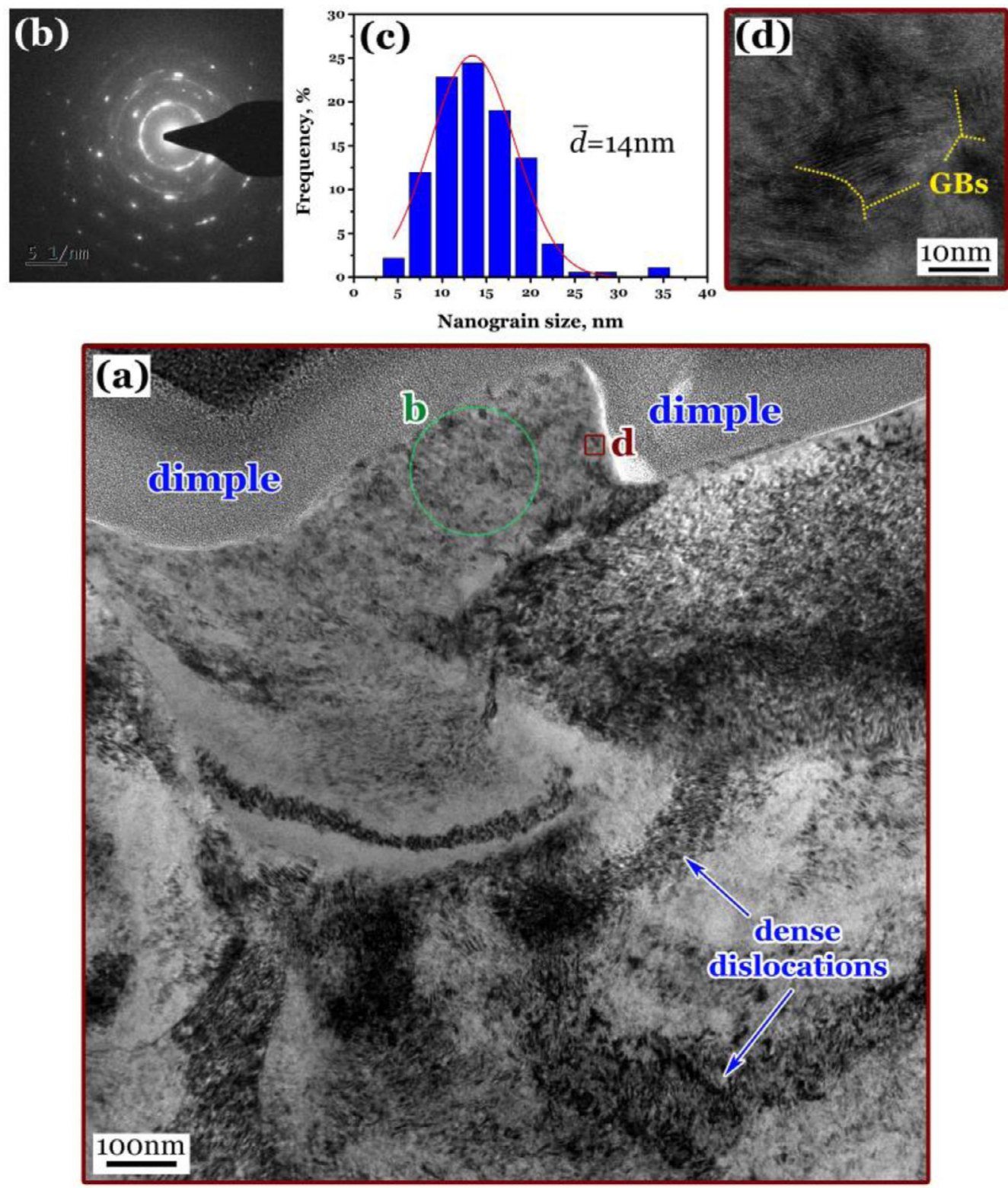

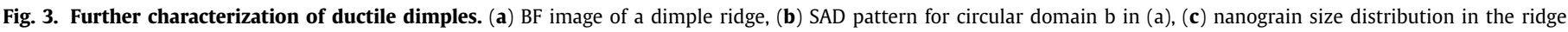
region, and (d) HRTEM image of box $d$ in (a).

to the stage of post uniform deformation, and the specimen will become necking. In the necking part of the specimen (Fig. 4a), the normal stress $\sigma$ along the loading axis increases with the decrease of the cross section area. This is accompanied by the introduction of triaxial stress state on the cross section of the necked part. In general, beyond the UTS point, the nucleated microvoids will grow, gradually coalesce together and eventually lead to final fracture $[14,17]$. Fig. $4 \mathrm{~b}$ and c is SEM images of longitudinal sections b and $c$ of a tested specimen within the necking part, with section $\mathrm{c}$ being experienced more severe necking process. Fig. $4 \mathrm{~b}$ shows a pattern of void early growth containing several voids with three indicated by arrows: two of several micrometers and the third one of submicron size in the EM matrix. Fig. 4c shows a pattern of void coalescence containing the dimples resulted from the merged microvoids. The internal crack of coalesced microvoids shown in Fig. $4 \mathrm{c}$ is about $80 \mu \mathrm{m}$ in size, which is quite large in the case of monotonic tension. For the void nucleation and growth under a triaxial stress state, the applied stress at far field is denoted as $\sigma_{\mathrm{i}}$, and the local stress at the localized area of a growing dimple is $\sigma_{\mathrm{v}}$. According to the theories of stress concentration and elasticplastic fracture mechanics, during the strain localization, $\sigma_{\mathrm{v}}$ will tend to a very large value at the dimple ridge as shown in Fig. 4e. For the mechanism of SPD [9-11], the very large value of $\sigma_{\mathrm{v}}$ will cause the related very high strain, which is quite sufficient to produce nanograins at the ridge area. As noted, such an SPD process only occurs in a relatively small region in the tearing ridge area of ductile dimples, so it is named as LSPD.

In summary, we reported, the first time, nanograin formation in the tearing ridge of dimples on the fracture surface of a titanium alloy, which is very likely to happen in other ductile materials. Such type of nanograin formation is caused by the process of LSPD under monotonic tension, which is a new kind of SPD mechanism. The process of microstructure refinement and nanograin formation is an essential part within the whole course of ductile fracture especially in the post uniform deformation after specimen necking. Based on the present findings, one may have the prospect of de- 
(a)

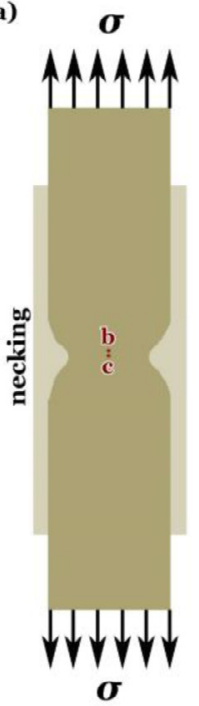

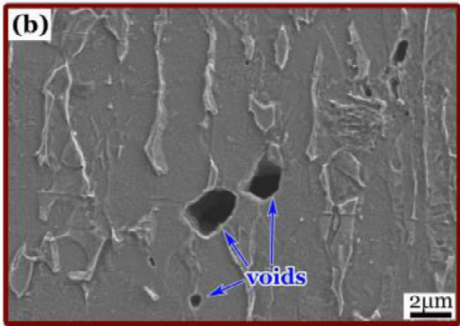

(c)

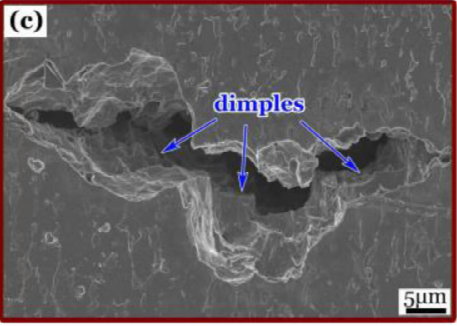

(d)

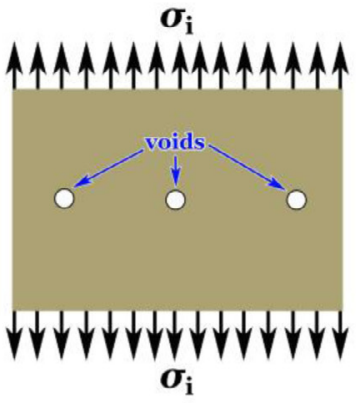

(e)

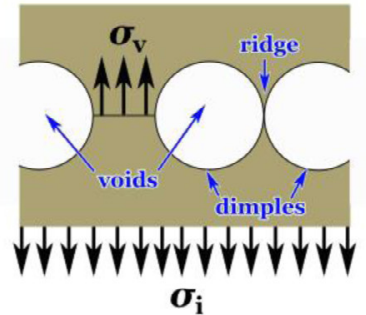

necking

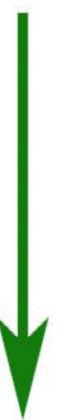

fracture

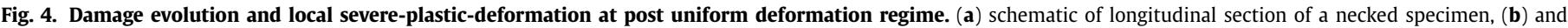
(c) SEM images of points b and c shown in (a), void nucleation (d), growth and coalescence (e) from necking to fracture.

signing a new series of metallic materials with high ductility by the in-situ strain energy consumption thanks to the process of microstructure refinement and nanograin formation, which will happen in the stage of post uniform deformation caused by the mechanism of LSPD at dimple ridges as an example. It is also anticipated that this process of in-situ strain energy consumption by the process of microstructure refinement and nanograin formation may happen even in the uniform deformation stage. Thus it will create a plenty room for ductility improvement for metallic materials.

\section{Data and materials availability}

The data that support the findings of this study are available from the corresponding author upon reasonable request.

\section{Declaration of Competing Interest}

The authors declare that they have no known competing financial interests or personal relationships that could have appeared to influence the work reported in this paper.

\section{Acknowledgments}

The authors would like to acknowledge the financial support from the National Natural Science Foundation of China (11932020) and from the Strategic Priority Research Program of the Chinese Academy of Sciences (XDB22040503, XDB22020201).

\section{References}

[1] M.A. Meyers, A. Mishra, D.J. Benson, Prog. Mater. Sci. 51 (2006) 427-556.

[2] H. Gleiter, Prog. Mater. Sci. 33 (1989) 223-315.

[3] K.S. Kumar, H. Van Swygenhoven, S. Suresh, Acta Mater. 51 (2003) 5743-5774.

[4] E.O. Hall, Proc. Phys. Soc. B 64 (1951) 747-753.
[5] N.J. Petch, J. Iron Steel Inst. 174 (1953) 25-28.

[6] Y.M. Wang, M.W. Chen, F.H. Zhou, E. Ma, Nature 419 (2002) 912-915.

[7] Y.M. Wang, E. Ma, Acta Mater. 52 (2004) 1699-1709.

[8] L. Lu, Y.F. Shen, X.H. Chen, L.H. Qian, K. Lu, Science 304 (2004) 422-426.

[9] R.Z. Valiev, R.K. Islamgaliev, I.V. Alexandrov, Prog. Mater. Sci. 45 (2000) 103-189.

[10] R.Z. Valiev, Nature Mater. 3 (2004) 511-516.

[11] R.Z. Valiev, T.G. Langdon, Prog. Mater. Sci. 51 (2006) 881-981.

[12] E. Bagherpour, E. Pardis, M. Reihanian, R. Ebrahimi, Int. J. Adv. Manuf. Tech. 100 (2019) 1647-1694.

[13] P. Wang, T.H. Yin, S.X. Qu, Scr. Mater. 178 (2020) 171-175.

[14] M.A. Meyers, K.K. Chawla, Mechanical Behavior of Materials, Second ed., Cambridge University Press, Cambridge, 2008.

[15] G.R. Irwin, J. Appl. Mech. - T. ASME 24 (1957) 361-364.

[16] J.R. Rice, J. Appl. Mech. - T. ASME 35 (1968) 379-386.

[17] T.L. Anderson, Fracture Mechanics: Fundamentals and Applications, Third ed., Taylor \& Francis, Boca Raton, 2005.

[18] F.A. McClintock, J. Appl. Mech. - T. ASME 35 (1968) 363-371.

[19] A.L. Gurson, J. Eng. Mater. - T. ASME 99 (1977) 2-15.

[20] A.A. Benzerga, J. Mech. Phys. Solids 50 (2002) 1331-1362.

[21] S.W. Tu, X.B. Ren, J.Y. He, Z.L. Zhang, Fatigue Fract, Fatigue Fract. Eng. Mater. Struct. 43 (2020) 3-19.

[22] A. Pineau, A.A. Benzerga, T. Pardoen, Acta Mater. 107 (2016) 424-483.

[23] J. Wang, F. Sansoz, J. Huang, Y. Liu, S. Sun, Z. Zhang, S.X. Mao, Nat. Commun. 4 (2013) 1742 .

[24] A. Taloni, M. Vodret, G. Costantini, S. Zapperi, Nat. Rev. Mater. 3 (2018) 211-242.

[25] A. Barrios, S. Gupta, G.M. Castelluccio, O.N. Pierron, Nano Lett. 18 (2018) 2595-2602.

[26] R. Pippan, C. Zelger, E. Gach, C. Bichler, H. Weinhandl, Fatigue Fract. Eng. Mater. Struct. 34 (2011) 1-16.

[27] D. Infante-García, E. Giner, H. Miguélez, M.A. Wahab, Tribol. Int. 135 (2019) 121-129.

[28] M.F. Ashby, Materials Selection in Mechanical Design, Fourth ed., Elsevier, Amsterdam, 2011.

[29] D. Hull, D.J. Bacon, Introduction to Dislocations, Fifth ed., Elsevier, Amsterdam, 2011.

[30] A.J. Schwartz, M. Kumar, B.L. Adams, D.P. Field, Electron Backscatter Diffraction in Materials Science, Second ed., Springer, New York, 2009.

[31] Y. Hong, X. Liu, Z. Lei, C. Sun, Int. J. Fatigue 89 (2016) 108-118.

[32] Y. Hu, C. Sun, Y. Hong, Fatigue Fract. Eng. Mater. Struct. 41 (2018) 1717-1732.

[33] X. Pan, H. Su, C. Sun, Y. Hong, Int. J. Fatigue 115 (2018) 67-78.

[34] X. Pan, Y. Hong, Fatigue Fract. Eng. Mater. Struct. 42 (2019) 1950-1964. 